\title{
Thyroid hormones and aging
}

\author{
Robin P. Peeters
}

Department of Internal Medicine, Erasmus University Medical Center, Rotterdam, the Netherlands

\begin{abstract}
With an increase in age, marked changes in thyroid hormone production, metabolism, and action occur. This results in an increased prevalence of (subclinical) thyroid disease in the elderly. In general, subclinical thyroid disease is associated with an increased risk of overt thyroid dysfunction and with different negative clinical parameters. In the elderly, however, it is unclear whether these changes represent physiologic changes in thyroid hormone levels with advancing age or whether they represent true (subclinical) thyroid disease. This review describes the changes in thyroid hormone levels with aging and the mechanisms behind these changes, and also discusses whether subclinical thyroid disease should be treated in the elderly.
\end{abstract}

Key words: Elderly, Hyperthyroidism, Hypothyroidism, Metabolism, Subclinical

\section{INTRODUCTION}

Several changes in thyroid function and thyroid function tests occur with advancing age, as reviewed by Mariotti et $\mathrm{al}^{1}$ and Adler et $\mathrm{al}^{2}$ Studies on the natural course of thyroid function tests in the elderly are often complicated by confounding factors such as the increased prevalence of autoimmune subclinical hypothyroidism, of chronic (non-thyroidal) illness and of medication induced changes in thyroid function tests. ${ }^{1,-5}$ After exclusion of these confounders, most studies show similar results: A clear, age-dependent decline in serum Thyroid Stimulating Hormone (TSH) and (free) T3, whereas serum (free) T4 levels remain unchanged. The inactive metabolite rT3 seems to increase with age ${ }^{1}$ (Figure 1).

Address for correspondence:

Robin P. Peeters, M.D., PhD, Department of Internal

Medicine, Room Ee 502, Erasmus University Medical Center,

Dr. Molewaterplein 40, 3015 GD Rotterdam, the Netherlands,

Tel.: 31-10-4635463; Fax: 31-10-4635430,

e-mail: r.peeters@erasmusmc.nl

Received 30-09-07, Revised 10-11-07, Accepted 05-12-07

\section{Mechanisms behind the changes in TSH and thyroid hormone levels in the elderly}

Serum TSH concentrations decrease in healthy elderly subjects due to an age-related decrease in TSH secretion by the pituitary. ${ }^{6}$ Furthermore, the nocturnal TSH peak is blunted and there is a 1-1.5 hour shift in the circadian rhythm of TSH secretion, resulting in an earlier peak. ${ }^{7,8}$ The mechanism of this reduction in TSH secretion is currently unknown. It may very well be an increased sensitivity of the thyrotrophes to the negative feedback by T4, but other mechanisms such as a reduced hypothalamic Thyrotropine Releasing Hormone (TRH) secretion cannot be excluded. ${ }^{1}$

Although reduced TSH levels result in a reduced thyroidal T4 secretion in the elderly, ${ }^{9,10}$ serum total and free T4 (FT4) concentrations remain unchanged., ${ }^{1,2}$ This is because $\mathrm{T} 4$ degradation by outer ring deiodination decreases with age. ${ }^{9-11}$ Outer ring deiodination, catalyzed by the deiodiniases type 1 and type 2 (D1 and D2), is responsible for the conversion of $\mathrm{T} 4$ to 


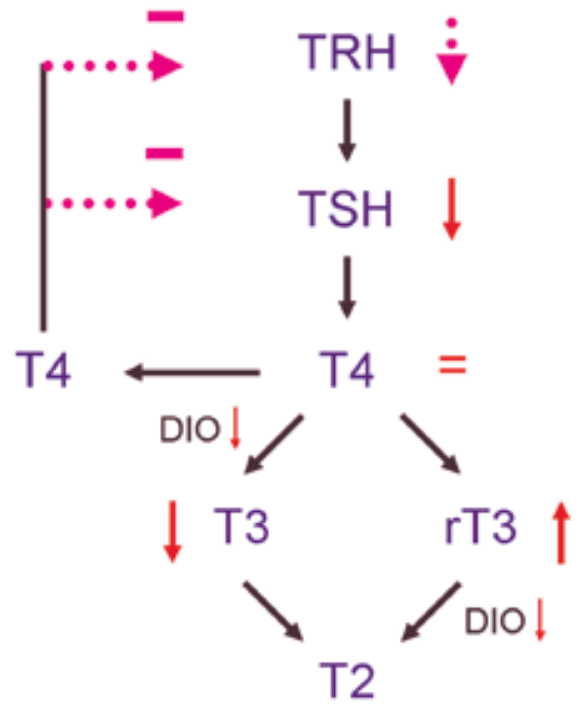

Figure 1. The changes that occur in thyroid function tests with advancing age. There is an age-dependent decline in serum TSH and (free) T3. The reduction in TSH secretion may very well be due to an increased sensitivity of the thyrotrophes to the negative feedback by T4, but other factors such as a reduced hypothalamic TRH secretion cannot be excluded (shown in purple). Although reduced TSH levels result in a reduced thyroidal T4 secretion in the elderly, serum total and free T4 (FT4) concentrations remain unchanged. This is because T4 degradation by outer ring deiodination decreases with age. The inactive metabolite rT3 seems to increase with age.

$\mathrm{T} 3$ and for the clearance of the inactive metabolite rT3. ${ }^{12}$ The net result of this decreased deiodination with advancing age is a clear, age-dependent decline in total and free T3 levels up to 100 years or more, and an increase in serum rT3 levels. ${ }^{1,4}$ It is currently unknown whether an increased inner ring deiodination by D3, which would result in an increased clearance of $\mathrm{T} 4$ and $\mathrm{T} 3$ and an increased production of $\mathrm{rT} 3$, also contributes to these changes. This has recently been shown to be a major factor in non-thyroidal illness. ${ }^{13,14}$

There is an age-dependent increase in the prevalence of positive anti-thyroperoxidase (anti-TPO) and anti-thyroglobulin (anti-Tg) antibodies, especially in females over 60 years of age. ${ }^{15-19}$ This results in an increased prevalence of subclinical hypothyroidism..$^{19,20}$ An increase in TSH levels in the elderly, as described in some studies, ${ }^{19,21}$ is therefore thought to be primarily due to the inclusion of women with thyroid antibodies and/or (subclinical) hypothyroidism in those studies. ${ }^{1,2,19,22}$ Interestingly, thyroid antibodies are rare in centenarians and other highly selected groups of elderly, while they are rather frequently observed in hospitalized or other unselected elderly subjects. ${ }^{1,23,24}$

\section{Confounders in thyroid function tests in the elderly}

Fasting and acute and chronic illness are associated with a decreased serum T3 and increased rT3, without any evidence of thyroid disease. ${ }^{13,25-30}$ This is often referred to as non-thyroidal illness. The high prevalence of non-thyroidal illness, due to malnutrition and the presence of chronic illness, is an important confounder in the assessment of thyroid function in the elderly. ${ }^{1,3}$ This is illustrated by a recent study in 403 healthy ambulatory men (aged 73-94 years), in which subjects with systemic infectious, inflammatory, and malignant disorders were excluded. In this study, 63 men met the criteria for non-thyroidal illness, ${ }^{3}$ which was defined as a low serum T3 and a high serum rT3. Those subjects were older and had more frequently such diseases as hypertension, atherosclerosis, mild congestive heart failure, chronic obstructive pulmonary disease, diabetes and/or arthritis. ${ }^{3}$ Interestingly, independent of disease, high rT3 was associated with a low performance score. This might be due to nutritional status, since caloric deprivation is known to result in an increase in serum rT3 levels. ${ }^{25,28,31} \mathrm{~A}$ reduced selenium intake, in addition to other factors such as iodine intake, seems to be important here, since the trace element selenium is essential for the deiodination of thyroid hormone. . $2,32,33$

In addition to malnutrition and illness, use of medication may influence thyroid function tests in the elderly. It is well known that there is a strong positive relation between age and medication use. ${ }^{34}$ Drugs can cause hypothyroidism (e.g. lithium), hyperthyroidism (e.g. amiodarone) or abnormal thyroid function tests without a direct effect on thyroid function by affecting TBG status (e.g. glucocorticouds, estrogens), or the binding of T4 to TBG (e.g. heparin), by suppressing TSH secretion (e.g. glucocorticoids, dopamine) or by suppressing T4 to T3 conversion (e.g. glucocorticoids, amiodarone, propanolol). Therefore, such factors must be considered in interpreting altered thyroid function tests in the elderly. Also, other parameters, 
such as genetic variation and psychological factors, may influence thyroid function tests in the elderly. In the last few years, evidence has emerged that genetic factors, and thus genetic polymorphisms in thyroid hormone pathway genes, are major contributors to the variation in thyroid function tests between different individuals. ${ }^{35-38}$ In elderly subjects, polymorphisms in thyroid hormone pathway genes have been associated with serum T3 levels, body composition, and insulin resistance. ${ }^{39,40}$

\section{SUBCLINICAL THYROID DISEASE IN THE ELDERLY}

\section{Hyperthyroidism}

The prevalence of hyperthyroidism in the elderly is increased, with frequencies ranging from $0.5-3 \%$ in populations older than 60 years of age..$^{1,19,20,41}$ All types of hyperthyroidism occur in the elderly. Toxic multinodular goiter is the most frequent cause of spontaneous hyperthyroidism in the elderly in areas with a low iodine intake, whereas Graves' disease is more common in areas with a relatively high iodine intake such as the United States. ${ }^{1,41,42}$ In aged patients, hyperthyroidism may also be precipitated by excess iodine intake from drugs or radiographic contrast agents. ${ }^{1}$

When compared to younger patients, elderly hyperthyroid patients display fewer signs and symptoms. ${ }^{1,43}$ They often lack a tremor, heat intolerance, ocular signs, nervousness or tachycardia. However, the frequency of atrial fibrillation is higher. Unexplained weight loss, with diarrhea but also with constipation, nausea, and vomiting may be the dominant picture. ${ }^{1,43}$ In addition, depression and mania can be manifestations of hyperthyroidism in the elderly.

Administration of ${ }^{131} \mathrm{I}$, often combined with $\beta$ blocking agents, is the treatment of choice in most cases of hyperthyroidism in the elderly.

\section{Subclinical hyperthyroidism}

Subclinical hyperthyroidism is defined as a low serum TSH, combined with a FT4 and FT3 in the reference range. ${ }^{2,44}$ Especially in the elderly, other causes of a low TSH such as non-thyroidal illness, fasting, and the administration of drugs (e.g. glucocorticoids) should be excluded before making the diagnosis. With a prevalence of $3.2 \%$, and of $2 \%$ after the exclusion of subjects with known thyroid disease, subclinical hyperthyroidism is much less frequent than subclinical hypothyroidism..$^{20,44}$ The prevalence may be up to $6.3 \%$ in the elderly, being more frequent in females, in blacks, and in populations with a low iodine intake. ${ }^{42,44,45}$ The most common etiologies of subclinical hyperthyroidism are similar to the above-mentioned causes of hyperthyroidism. In addition, (usually unintended) thyroid hormone suppression therapy is frequently a cause of subclinical hyperthyroidism in the elderly. ${ }^{41,46-48}$

Approximately $1-2 \%$ of patients over 60 years of age with subclinical hyperthyroidism progress to overt hyperthyroidism. ${ }^{45,49}$ Progression rarely occurs in patients with a serum TSH between 0.1 and $0.45 \mathrm{mU} / \mathrm{L},{ }^{44,45,50}$ while in a substantial proportion of elderly patients TSH values normalize. ${ }^{49,51,52}$ Before considering treatment of patients with a suppressed $\mathrm{TSH}$, other causes should be excluded. It should be underlined that non-thyroidal illness and use of TSH suppressing drugs hardly ever result in a TSH level below $0.1 \mathrm{mU} / \mathrm{L} .^{13}$

In addition to progression to overt hyperthyroidism, other possible consequences of subclinical hyperthyroidism would be cardiac dysfunction, atrial fibrillation, other adverse cardiac endpoints, systemic and neuropsychiatric symptoms, and a reduced bone mineral density. ${ }^{44,51-61}$ Nevertheless, in two recent reviews of the literature it was concluded that evidence regarding the benefit of treatment in patients who are found to have subclinical hyperthyroidism by screening is insufficient or absent, except for bone mineral density. ${ }^{44,62}$

Current guidelines following a consensus conference make a clear distinction between exogenous and endogenous subclinical hyperthyroidism. In endogenous subclinical hyperthyroidism, patients should be divided into one group with a TSH below $0.1 \mathrm{mU} / \mathrm{L}$ and another group between $0.1 \mathrm{mU} / \mathrm{L}$ and $0.45 \mathrm{mU} / \mathrm{L} .{ }^{44,63}$ In patients with TSH levels of 0.1-0.45 mU/L, the panel advised against routine treatment, since there was insufficient evidence to establish a clear association between this mild degree of hyperthyroidism and adverse clinical outcomes, including atrial fibrillation. ${ }^{44}$ Interestingly, a very 
recent study not only confirmed that subclinical hyperthyroidism is associated with atrial fibrillation on resting electrocardiogram, but also demonstrated that FT4 levels are independently associated with atrial fibrillation, even in euthyroid subjects with normal serum TSH levels. ${ }^{64}$ In addition, two recent observational studies in elderly subjects (of $>73$ years and of $>85$ years of age) have shown that increasing TSH and/or decreasing FT4 levels are associated with a lower mortality rate. ${ }^{3,65}$ These data combined with the association of subclinical hyperthyroidism and increased cardiovascular mortality ${ }^{54}$ may lead to the consideration of treatment even in mild subclinical hyperthyroidism in the elderly, despite the lack of evidence from intervention trials. ${ }^{2,44,65}$

In patients with a TSH $<0.1 \mathrm{mU} / \mathrm{L}$ due to Graves' or nodular thyroid disease, the panel recommended the consideration of treatment, especially in subjects older than 60 years. ${ }^{44}$ Although there is a lack of intervention trials showing beneficial effects (except for the stabilization of bone loss) ${ }^{66,67}$ the concern about the risk of atrial fibrillation and/or bone loss in the elderly convinced the panel to recommend the consideration of treatment. ${ }^{44}$

\section{Hypothyroidism in the elderly}

The frequency of overt hypothyroidism, which is 5 to 8 times more common in women than men, varies from 0.1 to $2 \%$, with an increased prevalence of up to $5 \%$ in subjects over 60 years of age. ${ }^{1,50}$ Hypothyroidism in the elderly is often atypical and lacks the classic symptoms seen in younger patients. ${ }^{1}$ This is due to a more insidious onset, the co-existence of several ageassociated diseases, and the notion that several signs and symptoms (fatigue, cold intolerance, constipation, congestive heart failure, depression, etc) may be attributed to the process of aging itself. The most frequent cause is autoimmune thyroiditis, followed by prior therapy for previous thyrotoxicosis. ${ }^{1,68}$

The treatment of hypothyroidism at any age requires thyroid hormone replacement therapy. ${ }^{1}$ Thyroid hormone increases myocardial oxygen demand, which may induce angina pectoris, myocardial infarction or cardiac arrhythmias in older patients. Therefore, in elderly patients, and even more so in elderly patients with coronary disease or multiple coronary risk factors, thyroid hormone replacement should be initiated conservatively. ${ }^{1,69}$ One prospective study, in which 50 hypothyroid patients were randomly assigned to a full starting dose of levothyroxine or to levothyroxine $25 \mathrm{mcg} /$ day with dose adjustments every four weeks, showed no adverse cardiac effects in those patients who received a full starting dose.$^{70}$ However, the oldest patient included in the full dose group of this study was 86 years of age and all patients with a known history of cardiac disease or those taking cardiac medication were excluded. In addition, signs and symptoms of hypothyroidism and quality of life improved at a comparable rate in both groups. ${ }^{70}$

It is generally advised that elderly hypothyroid patients are given a lower dose than younger adults to compensate for the physiological age-associated reduction in T4 production. ${ }^{1,71-74}$ An interesting observation in older hypothyroid patients is the narrow range between TSH suppression and substitution dose, which may be due to an increased sensitivity of the thyrotrophes to the negative feedback by T4. Close monitoring is nevertheless required to avoid overtreatment. ${ }^{1}$ An extra justification for giving a lower dose in the very old is the fact that two recent observational studies (in subjects $>73$ years and in subjects $>85$ years) have shown that high TSH and/or low FT4 levels are associated with a lower mortality rate. ${ }^{3,65}$

\section{Subclinical hypothyroidism in the elderly}

The link between autoimmune thyroiditis and aging is illustrated by the high prevalence of subclinical hypothyroidism with positive autoantibodies in the elderly. ${ }^{20,44}$ Subclinical hypothyroidism is by definition a laboratory diagnosis and is defined as an elevated TSH combined with a normal FT4. ${ }^{44,75}$ The frequency of subclinical hypothyroidism varies from $4 \%$ to $8.5 \%$ in different populations, ${ }^{20,44,50,76,77}$ with an increasing frequency in older subjects. In women aged $>60$ years, subclinical hypothyroidism may be present in up to $20 \%,{ }^{21,44,45,76}$ and in elderly men in up to $8 \% .^{21}$ The prevalence is lower in blacks than in whites, ${ }^{20}$ in women over 80 years of age, ${ }^{45}$ and in populations with iodine deficiency. ${ }^{44}$

The natural history of subclinical hypothyroidism in subjects older than 55 years is progression to overt hypothyroidism at a rate of approximately $8 \%$ per year. The magnitude of TSH elevation at baseline 
is the most powerful predictor for progression, but the presence of symptoms of hypothyroidism, goiter, positive thyroid antibodies, and a low normal FT4 also affect the outcome. ${ }^{78}$ Interestingly, in the same study TSH levels normalized in $37 \%$ of patients after an average follow-up of 31.7 months. ${ }^{78}$ Whether or not subclinical thyroid dysfunction should be treated has been a matter of debate for years. Possible consequences of subclinical hypothyroidism include cardiac dysfunction, atherosclerosis, elevated total and LDL cholesterol, neuropsychiatric symptoms, and progression to overt hypothyroidism. ${ }^{44,50,54,58,76,79}$ In two recent reviews of the literature, it was concluded that evidence regarding the efficacy of treatment in patients who are found to have subclinical hypothyroidism by screening is inconclusive. ${ }^{44,62}$ Data relating a serum TSH concentration above $10 \mathrm{mU} / \mathrm{L}$ to higher cholesterol levels were rated as fair, but data on the benefits of treatment were rated as insufficient. ${ }^{44}$ All other associations of symptoms, as well as of benefits of treatment, were rated as insufficient. ${ }^{44,62}$

Current guidelines therefore do not recommend routine thyroid hormone substitution in subjects with normal FT4 levels and a TSH below $10 \mathrm{mU} / \mathrm{L}$. Thyroid function tests with a 6-12 month interval are recommended to monitor the course of the serum TSH level., ${ }^{2,4}$ In individual patients with hypothyroid symptoms, a trial of thyroid hormone substitution for several months may be considered. Still, the likelihood of improvement is small and must be balanced against potential risks of therapy. ${ }^{44}$ In patients with a TSH $>10 \mathrm{mU} / \mathrm{L}$ thyroxine therapy can be considered as reasonable due to the high progression rate to overt hypothyroidism. ${ }^{2,44}$ This is especially true in women of over 60 years of age who have positive antibodies. ${ }^{78,80}$ However, in the very old, thyroid hormone substitution is not likely to be beneficial. It may even be harmful, since two recent observational studies (in subjects $>73$ years and in subjects $>85$ years) have shown that high TSH and/or low FT4 levels are associated with a lower mortality rate.,

\section{CONCLUSIONS}

In conclusion, aging results in a decrease in serum TSH and T3 levels, whereas serum FT4 levels usually remain unchanged. Nutritional status, illness, and the use of medication are common confounders in the determination of thyroid status in the elderly. Currently available data do not lead to definitive conclusions with regard to the treatment of subclinical thyroid disease in the elderly. In general, it can be concluded that the treatment of pronounced subclinical thyroid disease (TSH $<0.1 \mathrm{mU} / \mathrm{L}$ or TSH $>10 \mathrm{mU} / \mathrm{L}$ ) should be considered, based on a combination of age, complaints, and risk factors in the individual patients. With respect to mild subclinical thyroid disease (TSH $0.1-0.45 \mathrm{mU} / \mathrm{L}$ and TSH $4.5-10 \mathrm{mU} / \mathrm{L}$ ), the treatment of subclinical hyperthyroidism should be considered in the elderly, whereas subclinical hypothyroidism in the very old may be protective and should therefore not be treated.

\section{ACKNOWLEDGEMENTS}

The author would like to thank Professor T.J. Visser for critical reading of the manuscript.

\section{REFERENCES}

1. Mariotti S, Franceschi C, Cossarizza A, Pinchera A, 1995 The aging thyroid. Endocr Rev 16: 686-715.

2. Adler SM, Burman KD, 2007 Abnormalities in thyroid function parameters and subclinical thyroid disease in the elderly: a brief review. www.hotthyroidology.com

3. van den Beld AW, Visser TJ, Feelders RA, Grobbee DE, Lamberts SW 2005 Thyroid hormone concentrations, disease, physical function, and mortality in elderly men. J Clin Endocrinol Metab 90: 6403-6409.

4. Mariotti S, Barbesino G, Caturegli P, et al, 1993 Complex alteration of thyroid function in healthy centenarians. $\mathrm{J}$ Clin Endocrinol Metab 77: 1130-1134.

5. Chiovato L, Mariotti S, Pinchera A, 1997 Thyroid diseases in the elderly. Baillieres Clin Endocrinol Metab 11:251270.

6. van Coevorden A, Laurent E, Decoster C, et al, 1989 Decreased basal and stimulated thyrotropin secretion in healthy elderly men. J Clin Endocrinol Metab 69: 177-185.

7. van Coevorden A, Mockel J, Laurent E, et al, 1991 Neuroendocrine rhythms and sleep in aging men. Am J Physiol 260: E651-661.

8. Barreca T, Franceschini R, Messina V, Bottaro L, Rolandi E, 1985 24-hour thyroid-stimulating hormone secretory pattern in elderly men. Gerontology 31: 119-123.

9. Herrmann J, Heinen E, Kroll HJ, Rudorff KH, Kruskemper HL, 1981 Thyroid function and thyroid hormone metabolism in elderly people. Low T3-syndrome in old age? Klin Wochenschr 59: 315-323. 
10. Gregerman RI, Gaffney GW, Shock NW, Crowder SE, 1962 Thyroxine turnover in euthyroid man with special reference to changes with age. J Clin Invest 41: 20652074.

11. Inada M, Koshiyama K, Torizuka K, Akagi H, Miyake T, 1964 Clinical Studies on the Metabolism of 131-I-Labeled L-Thyroxine. J Clin Endocrinol Metab 24: 775-784.

12. Bianco AC, Salvatore D, Gereben B, Berry MJ, Larsen PR, 2002 Biochemistry, cellular and molecular biology, and physiological roles of the iodothyronine selenodeiodinases. Endocr Rev 23: 38-89.

13. Peeters RP, Wouters PJ, van Toor H, Kaptein E, Visser TJ, Van den Berghe G, 2005 Serum 3,3',5'-triiodothyronine (rT3) and 3,5,3'-triiodothyronine/rT3 are prognostic markers in critically ill patients and are associated with postmortem tissue deiodinase activities. J Clin Endocrinol Metab 90: 4559-4565.

14. Peeters RP, Wouters PJ, Kaptein E, van Toor H, Visser TJ, Van den Berghe G, 2003 Reduced activation and increased inactivation of thyroid hormone in tissues of critically ill patients. J Clin Endocrinol Metab 88: 32023211.

15. Tajiri J, Higashi K, Morita M, et al, 1984 Thyroid antibodies in healthy blood donors. Endocrinol Jpn 31: 837-843.

16. Hawkins BR, Cheah PS, Dawkins RL, et al, 1980 Diagnostic significance of thyroid microsomal antibodies in randomly selected population. Lancet 2: 1057-1059.

17. Hijmans W, Radl J, Bottazzo GF, Doniach D, 1984 Autoantibodies in highly aged humans. Mech Ageing Dev 26: 83-89.

18. Amino N, Mori H, Iwatani Y, Kawashima M, Miyai K, 1980 Significance of thyroid microsomal antibodies. Lancet 2: 1369.

19. Tunbridge WM, Evered DC, Hall R, et al, 1977 The spectrum of thyroid disease in a community: the Whickham survey. Clin Endocrinol (Oxf) 7: 481-493.

20. Hollowell JG, Staehling NW, Flanders WD, et al, 2002 Serum TSH, T(4), and thyroid antibodies in the United States population (1988 to 1994): National Health and Nutrition Examination Survey (NHANES III). J Clin Endocrinol Metab 87: 489-499.

21. Sawin CT, Chopra D, Azizi F, Mannix JE, Bacharach P, 1979 The aging thyroid. Increased prevalence of elevated serum thyrotropin levels in the elderly. JAMA 242: 247250.

22. Erfurth EM, Norden NE, Hedner P, Nilsson A, Ek L, 1984 Normal reference interval for thyrotropin response to thyroliberin: dependence on age, sex, free thyroxin index, and basal concentrations of thyrotropin. Clin Chem 30: 196-199.

23. Magri F, Muzzoni B, Cravello L, et al, 2002 Thyroid function in physiological aging and in centenarians: possible relationships with some nutritional markers. Metabolism 51: 105-109.

24. Mariotti S, Chiovato L, Franceschi C, Pinchera A, 1998
Thyroid autoimmunity and aging. Exp Gerontol 33: 535541.

25. Peeters RP, Debaveye Y, Fliers E, Visser TJ, 2006 Changes within the thyroid axis during critical illness. Crit Care Clin 22: 41-55.

26. Kaptein EM, Robinson WJ, Grieb DA, Nicoloff JT, 1982 Peripheral serum thyroxine, triiodothyronine and reverse triiodothyronine kinetics in the low thyroxine state of acute nonthyroidal illnesses. A noncompartmental analysis. J Clin Invest 69: 526-535.

27. Burger A, Nicod P, Suter P, Vallotton MB, Vagenakis P, Braverman L, 1976 Reduced active thyroid hormone levels in acute illness. Lancet 1: 653-655.

28. Docter R, Krenning EP, de Jong M, Hennemann G, 1993 The sick euthyroid syndrome: changes in thyroid hormone serum parameters and hormone metabolism. Clin Endocrinol (Oxf) 39: 499-518.

29. Chopra IJ, Smith SR, 1975 Circulating thyroid hormones and thyrotropin in adult patients with protein-calorie malnutrition. J Clin Endocrinol Metab 40: 221-227.

30. Chopra IJ, Chopra U, Smith SR, Reza M, Solomon DH, 1975 Reciprocal changes in serum concentrations of 3,3',5-triiodothyronine (T3) in systemic illnesses. J Clin Endocrinol Metab 41: 1043-1049.

31. Goichot B, Schlienger JL, Grunenberger F, Pradignac A, Sapin R, 1994 Thyroid hormone status and nutrient intake in the free-living elderly. Interest of reverse triiodothyronine assessment. Eur J Endocrinol 130: 244-252.

32. Kuiper GG, Kester MH, Peeters RP, Visser TJ, 2005 Biochemical mechanisms of thyroid hormone deiodination. Thyroid 15: 787-798.

33. Olivieri O, Girelli D, Stanzial AM, Rossi L, Bassi A, Corrocher R, 1996 Selenium, zinc, and thyroid hormones in healthy subjects: low T3/T4 ratio in the elderly is related to impaired selenium status. Biol Trace Elem Res 51: 31-41.

34. Willlams CM, 2002 Using medications appropriately in older adults. Am Fam Physician 66: 1917-1924.

35. Hansen PS, van der Deure WM, Peeters RP, et al, 2007 The impact of a TSH receptor gene polymorphism on thyroid-related phenotypes in a healthy Danish twin population. Clin Endocrinol (Oxf) 66: 827-832.

36. Hansen PS, Brix TH, Sorensen TI, Kyvik KO, Hegedus L, 2004 Major genetic influence on the regulation of the pituitary-thyroid axis: a study of healthy Danish twins. J Clin Endocrinol Metab 89: 1181-1187.

37. van der Deure WM, Peeters RP, Visser TJ, 2007 Genetic variation in thyroid hormone transporters. Best Pract Res Clin Endocrinol Metab 21: 339-350.

38. Peeters RP, van der Deure WM, Visser TJ, 2006 Genetic variation in thyroid hormone pathway genes; polymorphisms in the TSH receptor and the iodothyronine deiodinases. Eur J Endocrinol 155: 655-662.

39. Peeters RP, van der Deure WM, van den Beld AW, et al, 2007 The Asp727Glu polymorphism in the TSH receptor is associated with insulin resistance in healthy 
elderly men. Clin Endocrinol (Oxf) 66: 808-815.

40. Peeters RP, van den Beld AW, van Toor $\mathrm{H}$, et al, 2005 A polymorphism in type I deiodinase is associated with circulating free insulin-like growth factor I levels and body composition in humans. J Clin Endocrinol Metab 90: 256-263.

41. Diez JJ, 2003 Hyperthyroidism in patients older than 55 years: an analysis of the etiology and management. Gerontology 49: 316-323.

42. Laurberg P, Pedersen KM, Vestergaard H, Sigurdsson G, 1991 High incidence of multinodular toxic goitre in the elderly population in a low iodine intake area vs. high incidence of Graves' disease in the young in a high iodine intake area: comparative surveys of thyrotoxicosis epidemiology in East-Jutland Denmark and Iceland. J Intern Med 229: 415-420.

43. Trivalle C, Doucet J, Chassagne P, et al, 1996 Differences in the signs and symptoms of hyperthyroidism in older and younger patients. J Am Geriatr Soc 44: 50-53.

44. Surks MI, Ortiz E, Daniels GH, et al, 2004 Subclinical thyroid disease: scientific review and guidelines for diagnosis and management. JAMA 291: 228-238.

45. Parle JV, Franklyn JA, Cross KW, Jones SC, Sheppard MC, 1991 Prevalence and follow-up of abnormal thyrotrophin (TSH) concentrations in the elderly in the United Kingdom. Clin Endocrinol (Oxf) 34: 77-83.

46. Parle JV, Franklyn JA, Cross KW, Jones SR, Sheppard MC, 1993 Thyroxine prescription in the community: serum thyroid stimulating hormone level assays as an indicator of undertreatment or overtreatment. Br J Gen Pract 43: 107-109.

47. Ross DS, Daniels GH, Gouveia D, 1990 The use and limitations of a chemiluminescent thyrotropin assay as a single thyroid function test in an out-patient endocrine clinic. J Clin Endocrinol Metab 71: 764-769.

48. Batrinos ML, 2006 The problem of exogenous subclinical hyperthyroidism. Hormones (Athens) 5: 119-125.

49. Sawin CT, Geller A, Kaplan MM, Bacharach P, Wilson PW, Hershman JM, 1991 Low serum thyrotropin (thyroid-stimulating hormone) in older persons without hyperthyroidism. Arch Intern Med 151: 165-168.

50. Vanderpump MP, Tunbridge WM, French JM, et al, 1995 The incidence of thyroid disorders in the community: a twenty-year follow-up of the Whickham Survey. Clin Endocrinol (Oxf) 43: 55-68.

51. Stott DJ, McLellan AR, Finlayson J, Chu P, Alexander WD, 1991 Elderly patients with suppressed serum TSH but normal free thyroid hormone levels usually have mild thyroid overactivity and are at increased risk of developing overt hyperthyroidism. Q J Med 78: 77-84.

52. Sawin CT, Geller A, Wolf PA, et al, 1994 Low serum thyrotropin concentrations as a risk factor for atrial fibrillation in older persons. N Engl J Med 331: 1249-1252.

53. Bauer DC, Ettinger B, Nevitt MC, Stone KL, 2001 Risk for fracture in women with low serum levels of thyroidstimulating hormone. Ann Intern Med 134: 561-568.
54. Parle JV, Maisonneuve P, Sheppard MC, Boyle P, Franklyn JA, 2001 Prediction of all-cause and cardiovascular mortality in elderly people from one low serum thyrotropin result: a 10-year cohort study. Lancet 358: 861-865.

55. Samuels MH, 1998 Subclinical thyroid disease in the elderly. Thyroid 8: 803-813.

56. Auer J, Scheibner P, Mische T, Langsteger W, Eber O, Eber B, 2001 Subclinical hyperthyroidism as a risk factor for atrial fibrillation. Am Heart J 142: 838-842.

57. Biondi B, Palmieri EA, Fazio S, et al, 2000 Endogenous subclinical hyperthyroidism affects quality of life and cardiac morphology and function in young and middleaged patients. J Clin Endocrinol Metab 85: 4701-4705.

58. Biondi B, Palmieri EA, Lombardi G, Fazio S, 2002 Effects of subclinical thyroid dysfunction on the heart. Ann Intern Med 137: 904-914.

59. Schlote B, Nowotny B, Schaaf L, et al, 1992 Subclinical hyperthyroidism: physical and mental state of patients. Eur Arch Psychiatry Clin Neurosci 241: 357-364.

60. Kumeda Y, Inaba M, Tahara H, et al, 2000 Persistent increase in bone turnover in Graves' patients with subclinical hyperthyroidism. J Clin Endocrinol Metab 85: 4157-4161.

61. Pantazi H, Papapetrou PD, 2000 Changes in parameters of bone and mineral metabolism during therapy for hyperthyroidism. J Clin Endocrinol Metab 85: 1099-1106.

62. Helfand M, 2004 Screening for subclinical thyroid dysfunction in nonpregnant adults: a summary of the evidence for the U.S. Preventive Services Task Force. Ann Intern Med 140: 128-141.

63. Belaya ZE, Melnichenko GA, Rozhinskaya LY, et al, 2007 Subclinical hyperthyroidism of variable etiology and its influence on bone in postmenopausal women. Hormones (Athens) 6: 62-70.

64. Gammage MD, Parle JV, Holder RL, et al, 2007 Association between serum free thyroxine concentration and atrial fibrillation. Arch Intern Med 167: 928-934.

65. Gussekloo J, van Exel E, de Craen AJ, Meinders AE, Frolich M, Westendorp RG, 2004 Thyroid status, disability and cognitive function, and survival in old age. JAMA 292: 2591-2599.

66. Mudde AH, Houben AJ, Nieuwenhuijzen-Kruseman AC, 1994 Bone metabolism during anti-thyroid drug treatment of endogenous subclinical hyperthyroidism. Clin Endocrinol (Oxf) 41: 421-424.

67. Faber J, Jensen IW, Petersen L, Nygaard B, Hegedus L, Siersbaek-Nielsen K, 1998 Normalization of serum thyrotrophin by means of radioiodine treatment in subclinical hyperthyroidism: effect on bone loss in postmenopausal women. Clin Endocrinol (Oxf) 48: 285-290.

68. Diez JJ, 2002 Hypothyroidism in patients older than 55 years: an analysis of the etiology and assessment of the effectiveness of therapy. J Gerontol A Biol Sci Med Sci 57:M315-320.

69. Wartofsky L, 2005 Levothyroxine therapy for hypothyroidism: should we abandon conservative dosage titration? 
Arch Intern Med 165: 1683-1684.

70. Roos A, Linn-Rasker SP, van Domburg RT, Tijssen JP, Berghout A, 2005 The starting dose of levothyroxine in primary hypothyroidism treatment: a prospective, randomized, double-blind trial. Arch Intern Med 165: 1714-1720.

71. Davis FB, LaMantia RS, Spaulding SW, Wehmann RE, Davis PJ, 1984 Estimation of a physiologic replacement dose of levothyroxine in elderly patients with hypothyroidism. Arch Intern Med 144: 1752-1754.

72. Davis PJ, Davis FB, 1984 Hypothyroidism in the elderly. Compr Ther 10: 17-23.

73. Rosenbaum RL, Barzel US, 1982 Levothyroxine replacement dose for primary hypothyroidism decreases with age. Ann Intern Med 96: 53-55.

74. Sawin CT, Herman T, Molitch ME, London MH, Kramer SM, 1983 Aging and the thyroid. Decreased requirement for thyroid hormone in older hypothyroid patients. Am J Med 75: 206-209.

75. Col NF, Surks MI, Daniels GH, 2004 Subclinical thyroid disease: clinical applications. JAMA 291: 239-243.
76. Canaris GJ, Manowitz NR, Mayor G, Ridgway EC, 2000 The Colorado thyroid disease prevalence study. Arch Intern Med 160: 526-534.

77. Bagchi N, Brown TR, Parish RF, 1990 Thyroid dysfunction in adults over age 55 years. A study in an urban US community. Arch Intern Med 150: 785-787.

78. Diez JJ, Iglesias P, 2004 Spontaneous subclinical hypothyroidism in patients older than 55 years: an analysis of natural course and risk factors for the development of overt thyroid failure. J Clin Endocrinol Metab 89: 4890-4897.

79. Hak AE, Pols HA, Visser TJ, Drexhage HA, Hofman A, Witteman JC 2000 Subclinical hypothyroidism is an independent risk factor for atherosclerosis and myocardial infarction in elderly women: the Rotterdam Study. Ann Intern Med 132: 270-278.

80. Huber G, Staub JJ, Meier C, et al, 2002 Prospective study of the spontaneous course of subclinical hypothyroidism: prognostic value of thyrotropin, thyroid reserve, and thyroid antibodies. J Clin Endocrinol Metab 87: 32213226. 